\title{
Lignin-Carbohydrate Complexes Containing Phenolic Acids Isolated from the Culms of Bamboo ${ }^{\dagger}$
}

\author{
Jun-ichi Azuma, Takaya Nomura and Tetsuo KoshiJima \\ Wood Research Institute, Kyoto University, \\ Gokasho, Uji, Kyoto 611, Japan
}

Received March 11, 1985

\begin{abstract}
Lignin-carbohydrate complexes containing phenolic acids (LCC-W) were isolated from Mosobamboo (Phyllostachys pubescens Mazel) and characterized. LCC-W was separated into three fractions (W-1, 2, and 3) by gel filtration on Sepharose 4B. Of these three LCCs W-2 and W-3 were included in the gel matrices. W-2 consists of $34.7 \%$ neutral sugar, $1.6 \%$ uronic acid, $52.1 \%$ lignin, and $6.1 \%$ phenolic acid, and $\mathrm{W}-3,67.9 \%, 3.6 \%, 22.3 \%$, and $1.1 \%$, respectively. Neutral sugar residues of W-2 and W-3 were mainly L-arabinose and D-xylose in the ratios of $5.5: 94.3 \mathrm{in} \mathrm{W-2}$, and 4.5:95.0 in W-3, respectively. Methylation, periodate degradation, and NMR analyses indicated that the carbohydrate moiety of LCC-W is composed of a linear backbone of $\beta$ - $(1 \rightarrow 4)$-linked Dxylopyranose residues with approximately every thirty residues carrying one 4-O-methyl-Dglucuronic acid and one or two arabinofuranose residues. Saponified phenolic acids were composed of trans-p-coumaric and trans-ferulic acids, which seems to be esterified to carbohydrate and lignin, respectively. Alkaline treatment, periodate degradation, and hydrophobic interaction chromatography suggested the presence of alkali labile and stable lignin-carbohydrate linkages.
\end{abstract}

Lignin is a complex aromatic macromolecule that encrusts plant cell wall polysaccharides by possible covalent and physical bondings between lignin and carbohydrates., ${ }^{1,2)}$ Bamboo lignin is known to be peculiar in its structural monomeric units which comprise guaiacyl, syringyl, and $p$ hydroxyphenyl constituents. ${ }^{3,4)}$ Furthermore, bamboo lignin is known to contain $5 \sim 10 \%$ of $p$-coumaric acid which is absent in ordinary dicotyledonous lignins. ${ }^{5)}$ These unique characteristics of bamboo lignin are interesting and may help in elucidating the nature of the bondings between lignin, phenolic acid, and carbohydrates.

In our previous work, a new method was developed for isolation of lignin-carbohydrate complexes from pine ${ }^{6)}$ and this method has successfully been applied to beech, ${ }^{7)}$ and sugar cane bagasse. ${ }^{8)}$ This report deals with the isolation and characterization of lignin- carbohydrate complexes containing phenolic acids from the culms of a bamboo, Mosochiku (Phyllostachys pubescens Mazel).

\section{MATERIALS AND METHODS}

Solvents were removed under reduced pressure below $45^{\circ} \mathrm{C}$. Optical rotations were measured with a JASCO DIP-181 digital polarimeter at $25^{\circ} \mathrm{C}$. UV spectra were measured in $50 \%$ aqueous 1,4-dioxane using a JASCO UVDEC-420 spectrophotometer. IR spectra were taken as $\mathrm{KBr}$ discs using a JASCO IR-810 spectrophotometer. GLC was done with a Shimadzu GC-4CM or a GC-7AG with flame ionization detectors. Separations were done on glass columns $(0.3 \times 200 \mathrm{~cm})$ of (A) $3 \%$ ECNSS-M on Gas Chrom Q, (B) $3 \%$ OV-225 on Gas Chrom Q, (C) $20 \%$ tetramethyl cyclobutanediol adipate- $4 \%$ phosphoric acid on Chromosorb W, and (D) $5 \%$ OV-25 on Uniport HP, and (E) SP-1000 SCOT glass capillary column $(0.28 \mathrm{~cm}$ $25 \mathrm{~m})$. GLC-MS was done with a Shimadzu LKB-9000 system $(70 \mathrm{eV})$ using column (B) at $170^{\circ} \mathrm{C}$ and $150^{\circ} \mathrm{C}$. Analytical ultracentrifugation was done at $42,040 \mathrm{rpm}$ and $20^{\circ} \mathrm{C}$ in a Spinco model E ultracentrifuge with Schlieren

+ Part of this work was presented at the International Symposium on Carbohydrate Chemistry, Sydney, Australia, July $7 \sim 11,1980$. 
optics. ${ }^{13} \mathrm{C}$-NMR spectra were obtained on a Varian XL$200 \mathrm{NMR}$ spectrometer $(50.3 \mathrm{MHz})$ in deuterium oxide at $70^{\circ} \mathrm{C}$. Chemical shifts in ppm are given as the values relative to that of internal 1,4-dioxane $(67.4 \mathrm{ppm}$ from tetramethylsilane). TLC was done on Silica gel 60 (Merck 5715) using ethyl acetate-pyridine-water $(8: 2: 1, \mathrm{v} / \mathrm{v})$. PC was done on Whatman $3 \mathrm{MM}$ filter paper using 1-butanolpyridine-water $(6: 4: 3, \mathrm{v} / \mathrm{v})$. Sugars were detected with alkaline silver nitrate and $p$-anisidine hydrochloride. Total carbohydrate was measured by the phenol-sulfuric acid method, ${ }^{9)}$ uronic acid by the modified carbazole method, ${ }^{10}$ and lignin by the standard TAPPI (T-222os-74 and UM250) and acetyl bromide ${ }^{11)}$ methods. Zone electrophoresis was done on a Toyo GP-60 glass fiber paper in $0.05 \mathrm{M}$ borate buffer and $0.1 \mathrm{M}$ borax-sodium chloride buffer after staining the sample with Procion MX-R. ${ }^{12)}$ The acetyl content was measured by GLC on column (C) after hydrolysis of the sample with $1 \mathrm{~N}$ hydrochloric acid at $100^{\circ} \mathrm{C}$ for $2 \mathrm{hr}^{13)}$ Partially acetylated 4-O-methylglucurono-D-xylan $\left\{[\alpha]_{\mathrm{D}}^{20}-43.8^{\circ} \quad(c=0.75\right.$, methyl sulfoxide); $5.6 \%$ uronic acid and $6.0 \%$ of acetyl $\}$ was prepared from beech. ${ }^{14)}$

Isolation of lignin-carbohydrate complexes containing phenolic acids. The mature culms of Moso-chiku (Phyllostachys pubescens Mazel) were milled to $24 \sim$ 80 mesh, extracted with methanol-benzene $(1: 2, \mathrm{v} / \mathrm{v})$ for $48 \mathrm{hr}$ and depectinated with aqueous $0.25 \%$ potassium acetate at $60^{\circ} \mathrm{C}$ for $24 \mathrm{hr}$. The bamboo meal was then vibromilled for $48 \mathrm{hr}$ under a nitrogen atmosphere with external cooling by running water. The finely milled bamboo was extracted twice with 10 volumes of aqueous $80 \%$ dioxane for $48 \mathrm{hr}$ at room temperature. The extracts were concentrated to a small volume and thoroughly dialyzed against distilled water to remove insoluble milled bamboo lignin (MBL). The aqueous solution was lyophilized to give LCC-S. LCC-S was purified following the procedure previously described. ${ }^{6,7)}$ LCC-S was dissolved in aqueous $50 \%$ dioxane and extracted with chloroform to remove carbohydrate-less lignin. The aqueous layer was then dialyzed against distilled water and lyophilized to give LCC-SW. LCC-SW was dissolved in a solution of pyridine-acetic acid-water $(9: 1: 4, \mathrm{v} / \mathrm{v})$ and further purified by extraction with chloroform. The chloroform and the intermediate turbid layers were extracted several times with distilled water. The combined aqueous layers were dialyzed against distilled water and lyophilized to give LCC-W.

Fractionation of the lignin-carbohydrate complexes containing phenolic acids. Analytical gel filtration was done on columns of Sephadex G-100 $(60 \times 1.0 \mathrm{~cm})$ and Sepharose 4B $(55 \times 1.0 \mathrm{~cm})$ equilibrated with $0.025 \mathrm{M}$ sodium phosphate buffer (SPB), pH 6.8, and calibrated against dextrans of known molecular weights. Preparative gel filtration was done on a column $(94 \times 5.2 \mathrm{~cm})$ of Sepharose 4B using SPB as an eluent. The separated samples were dialyzed against distilled water and lyophilized. Elutions were monitored by measuring absorbances at $490 \mathrm{~nm}^{9)}$ for carbohydrate, $280 \mathrm{~nm}$ for lignin, and $315 \mathrm{~nm}$ for phenolic acid.

Hydrophobic interaction chromatography of the lignincarbohydrate complexes containing phenolic acids. Hydrophobic interaction chromatography was done on columns $(7 \times 1.8 \mathrm{~cm})$ of Phenyl- and Octyl-Sepharose CL4B (ligand concentration $40 \mu \mathrm{mole} / \mathrm{ml}$, Pharmacia) at $25^{\circ} \mathrm{C}^{6)}$ The columns were equilibrated with SPB. Each lignin-carbohydrate complex containing phenolic acids was dissolved in SPB and put on the column. The column was eluted with this buffer until no further absorption at $280 \mathrm{~nm}$ was detected to give fraction I. The column was then eluted with $50 \%$ 2-ethoxyethanol in SPB to give fraction II.

Sugar composition analyses. The sample was hydrolyzed with $0.5 \mathrm{M}$ sulfuric acid at $100^{\circ} \mathrm{C}$ for $6 \mathrm{hr}$, and the neutral sugars were converted into corresponding alditol acetates and separated by GLC on column (A). The neutral sugars were used for PC and TLC to give individual monosaccharides. The configuration of each monosaccharide was found by GLC on column (E) after conversion into acetylated-(+)-2-octyl D- and L-glycosides. Uronic acid was identified by GLC on column (A) after esterification with propylene oxide for 14 days at $25^{\circ} \mathrm{C},{ }^{15)}$ reduction with sodium borohydride, hydrolysis, and conversion into alditol acetate.

Alkali treatment of lignin-carbohydrate complexes containing phenolic acids. Esterified phenolic acid was measured by the procedure described by Hartley ${ }^{16)}$ and Hartley and Jones. ${ }^{17)}$ The sample was treated with $1.0 \mathrm{M}$ sodium hydroxide at $20^{\circ} \mathrm{C}$ for $24 \mathrm{hr}$. The hydrolysate was acidified to $\mathrm{pH} 2.5$ with $6 \mathrm{~m}$ hydrochloric acid, and the saponified phenolic acids were extracted with ethylether, trimethylsilylated, and separated by GLC on column (D).

LCC-W was also treated with $1 \mathrm{~m}$ sodium hydroxide-1 $\mathrm{M}$ sodium borohydride at $25^{\circ} \mathrm{C}$ for $12 \mathrm{hr}$. The clear solution was neutralized with acetic acid and centrifuged to remove the precipitate. The precipitate was thoroughly washed with distilled water; yield, $40.9 \%$. The molecular weight distribution and hydrophobic property of the watersoluble fraction as analyzed by gel filtration on Sepharose 4B and hydrophobic interaction chromatography on Octyl-Sepharose CL-4B, respectively.

Methylation analysis. Methylation was done by the method of Hakomori ${ }^{18)}$ followed by the method of Kuhn. ${ }^{19)}$ The methylated sample was hydrolyzed with $90 \%$ formic acid followed by $0.025 \mathrm{M}$ sulfuric acid following the procedure of Lindberg. ${ }^{20)}$ The partially methylated monosaccharides were converted into alditol acetates and analyzed by GLC on columns (A) and (B), and by GLC-MS on column (B). 
Periodate degradation analysis of the lignincarbohydrate complexes containing phenolic acids. The sample was deacetylated with $1.0 \mathrm{~m}$ sodium hydroxide and dialyzed against distilled water. The de-esterified sample was recovered by lyophilization. The native and deesterified samples were treated with $0.025 \mathrm{M}$ sodium metaperiodate for 10 days at $5^{\circ} \mathrm{C}$. Additional periodate was added to make $0.05 \mathrm{M}$ and the reaction was continued for another 10 days. The oxidation product was then reduced with sodium borohydride and hydrolyzed with $2 \mathrm{M}$ trifluoroacetic acid at $121^{\circ} \mathrm{C}$ for $1 \mathrm{hr}^{21)}$ The hydrolysate was converted into corresponding alditol acetates and analyzed by GLC on column (A) with a temperature program of $90 \sim 190^{\circ} \mathrm{C}$ at $6.0^{\circ} \mathrm{C} / \mathrm{min}$.

\section{RESULTS AND DISCUSSION}

Isolation of lignin-carbohydrate complexes containing phenolic acids.

The water soluble lignin-carbohydrate complexes containing phenolic acids (LCC-S) were isolated from the finely divided bamboo meal by extraction with aqueous $80 \%$ dioxane. These lignin-carbohydrate complexes containing phenolic acids were separated by treatment with chloroform and a pyridine-acetic acidchloroform system to LCC-SW and LCCW. The yield of these samples were 7.3

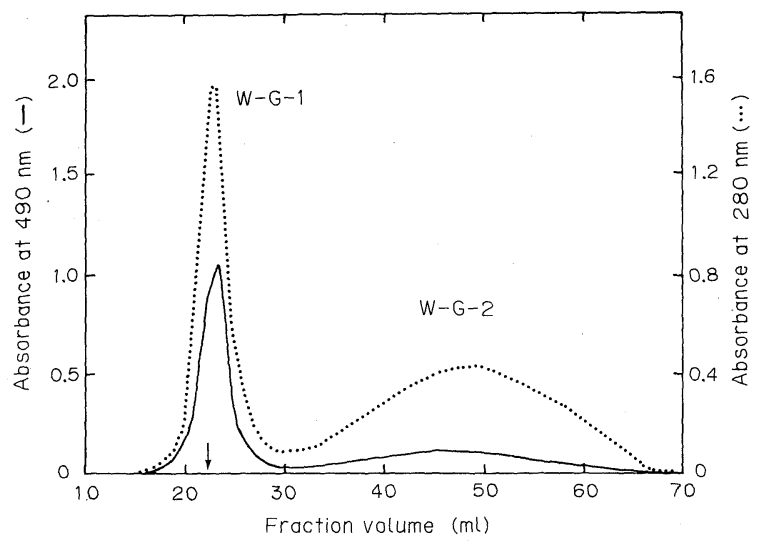

FIG. 1. Gel Filtration of Bamboo LCC-W on Sephadex G-100.

The arrow indicates the void volume. Elution was monitored for carbohydrate $(-)$ and lignin $(\cdots)$.

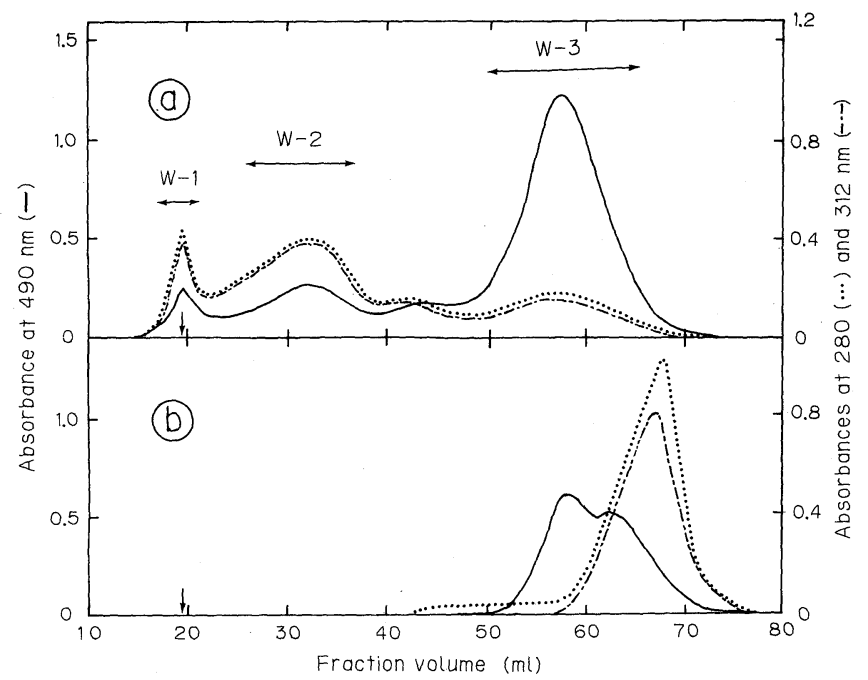

FIG. 2. Gel Filtration of Bamboo LCC-W on Sepharose 4B.

The arrow indicates the void volume. (a) and (b) indicate native LCC-W and alkali-treated LCC-W fractions, respectively. Elution was monitored for carbohydrate $(-)$, lignin $(\cdots)$, and phenolic acid $(---)$. 
(LCC-S), 5.8\% (LCC-SW), and 3.0\% (LCC$\mathrm{W})$, respectively, based on the depectinated bamboo meal. These values were similar to those of bagasse but $3 \sim 6$ times higher than those of pine and beech. ${ }^{6,7)}$ These results indicate the advantage of gramineous plants for structural analysis of lignin-carbohydrate complexes which contain a limited frequency of bonding between components.

A typical gel filtration profile of LCC-W on Sephadex G-100 (Fig. 1) showed two peaks, W-G-1 and W-G-2, the former was eluted at the void volume, while the latter was included in the gel matrices. Analytical gel filtration of LCC-W on Sepharose 4B showed, however, three distinct peaks; W-1, W-2, and W-3 (Fig. 2a). These three fractions were isolated by preparative scale gel filtration on Sepharose 4B in yields of $8.4 \%(\mathrm{~W}-1), 23.0 \%(\mathrm{~W}-2)$, and $51.7 \%(\mathrm{~W}-3)$ of LCC-W applied on the column. Rechromatography on an analytical Sephadex G-100 column showed that W-2 and W-3 eluted at the same positions of W-G-1 and $\mathrm{W}-\mathrm{G}-2$, respectively. The ratio of $\mathrm{W}-3$ to $\mathrm{W}-2$ (2.25) was intermediate between the ratios of pine $(1.1)^{6)}$ and beech (3.0). ${ }^{7)}$ The distribution profile of lignin overlapped with those of carbohydrate and phenolic acids, indicating the presence of lignin, phenolic acids, and carbohydrate in these samples. The elution profiles clearly showed that both W-1 and W-2 were rich in lignin and phenolic acids, whereas W-3 was rich in carbohydrate. The purified W-
2 and W-3 fractions gave single peaks in velocity sedimentation, sedimentation coefficients being $39.5 \mathrm{~S}(\mathrm{~W}-2)$ and $0.4 \mathrm{~S}(\mathrm{~W}-3)$ at infinite dilution. Both $\mathrm{W}-2$ and $\mathrm{W}-3$ moved toward the anode as an individual broad spots in glass fiber paper electrophoresis. These results indicate homogeneity in molecular weight and electric charge.

\section{Hydrophobic properties of lignin-carbohydrate complexes containing phenolic acids}

The bamboo lignin-carbohydrate complexes containing phenolic acids may be concerned with amphiphatic or surface active property because of the presence of hydrophilic carbohydrate and hydrophobic lignin in the same molecule. To verify this assumption and characterize the hydrophobic property, hydrophobic interaction chromatography was done using Phenyl- and Octyl-Sepharose CL-4B gel columns. Typical elution profiles obtained with LCC-W are shown in Fig. $3 a$ and $b$. Bamboo LCC-W, W-2, and W-3 were separated into two fractions each; unadsorbed fraction (I) and adsorbed fraction (II). The adsorbed materials were effectively desorbed with aqueous 50\% 2-ethoxyethanol. The amounts of adsorbed lignin were $83.8 \%$ (LCCW), $89.2 \%(\mathrm{~W}-2)$, and $58.3 \%(\mathrm{~W}-3)$ for Phenyl-Sepharose, and those for OctylSepharose were $80.9 \%$ (LCC-W), 93.7\% (W2 ), and $21.1 \%(\mathrm{~W}-3)$, respectively, of total lignin put on the gels. The amounts of ad-

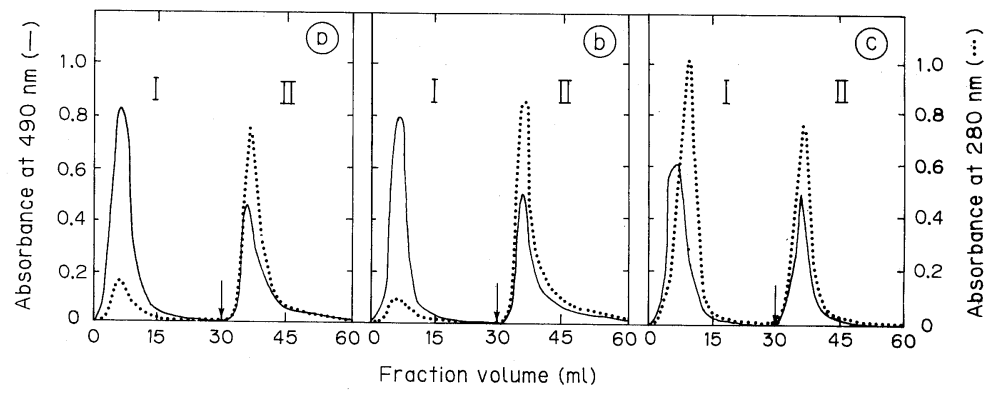

FIG. 3. Hydrophobic Interaction chromatography of Bamboo LCC-W.

(a), (b), and (c) indicate elution profiles of native LCC-W on Octyl-Sepharose CL-4B, native LCC-W on Phenyl-Sepharose CL-4B, and alkali-treated LCC-W on Octyl-Sepharose CL-4B, respectively. (I) and (II) indicate unadsorbed and adsorbed fractions, respectively. The arrows indicate the change of elution conditions. Elution was monitored for carbohydrate $(-)$ and lignin $(\cdots \cdots)$. 
sorbed carbohydrate were $37.9 \%$ (LCC-W), $82.7 \%(\mathrm{~W}-2)$, and $19.3 \%(\mathrm{~W}-3)$ for PhenylSepharose, and those for Octyl-Sepharose were $36.6 \%$ (LCC-W), 84.2\% (W-2), and $10.0 \%$ (W-3), respectively, of the total carbohydrate put on the gels. Previous studies on interactions between LCCs and hydrophobic gels ${ }^{6,22)}$ have shown that LCCs are linked to the hydrophobic gels mainly by hydrophobic interactions and that hydrogen bonds and electrostatic interactions are of minor importance. These results together with superposition of the two peaks due to lignin and carbohydrate exclude a mere physical mixture of lignin and carbohydrate and indicate the presence of chemical linkages between lignin, phenolic acids, and carbohydrates in the present LCCs. The amount of the adsorbed material increased with increase in lignin content in good agreement with results obtained for pine, beech, and bagasse. ${ }^{6 \sim 8)}$ The affinities of all samples tested for Phenyl-Sepharose were higher than or almost equivalent to those for Octyl-Sepharose, in spite of the fact that the hydrophobicity of the phenyl group is equivalent to a $4 \sim 5$ carbon straight chain hydrocarbon, ${ }^{23)}$ confirming the previous result that only hydrophobic interactions occur in the OctylSepharose, whereas in the Phenyl-Sepharose aromatic and aromatic $(\pi-\pi)$ interactions between lignin and benzene skeletons of the gel additionally occur. ${ }^{6,22)}$ The amounts of the adsorbed materials were independent on the structural differences of lignin and carbohydrates between gramineous plant, softwood, and hardwood. The adsorption of the sample on the hydrophobic gels may depend only on the lignin content. The hydrophobic interaction chromatography provides a new technique which fractionates electrophoretically and ultracentrifugically homogeneous lignincarbohydrate complexes with regard to lignin content.

\section{Chemical properties of the lignin-carbohydrate} complexes containing phenolic acids

The summative chemical analyses shown in Table I indicate that, in contrast to the lignin content, the neutral and uronic acid contents increased from $\mathrm{W}-1$ to $\mathrm{W}-3$ as expected from the gel filtration profiles (Figs. 1 and 2). The acetyl content and $[\alpha]_{D}$ value increased with the increase in carbohydrate content, suggesting that the optically active carbohydrate moiety was partially acetylated because of lack of optical activity in lignin. The presence of ester carbonyl groups $\left(1730 \mathrm{~cm}^{-1}\right)$ was also indicated. All lignin-carbohydrate complexes containing phenolic acids showed IR spectra including typical absorption bands of $O$ acetyl-4- $O$-methyl-glucurono-D-xylan and lignin (Fig. 4). The neutral carbohydrate moieties of all samples were commonly regarded as a hemicellulose, arabinoxylan, bearing only a few percent $(0.1 \sim 2.2 \%)$ of D-galactose and Dglucose (Table II). The acidic carbohydrate was found to be 4-O-methyl-D-glucuronic acid comprising $1.5 \sim 3.6 \%$ of the dry matter of the samples. In W-2 and W-3 fractions, the molar ratio of L-arabinose, D-xylose, and 4-Omethylglucuronic acid was $1.42 \sim 1.75: 30.0$ : $1.0 \sim 1.16$. The elemental analysis indicated that none of the bamboo lignin-carbohydrate complexes containing phenolic acids contained nitrogen. This shows that these samples are devoid of lignin-protein and/or carbohydrateprotein linkages which were reported to be present in poplar ${ }^{24)}$ and pine ${ }^{25)}$ callus tissues.

The UV spectra of all samples were similar to those of MBL and milled bagasse lignin, ${ }^{8)}$ and showed two peaks at $312 \mathrm{~nm}$ and 287 $289 \mathrm{~nm}$ (Fig. 5). Absorption at $312 \mathrm{~nm}$ was ascribed to esterified phenolic acids. ${ }^{5)}$ When LCC-W was treated with $1 \mathrm{M}$ sodium hydroxide to remove esterified phenolic acids, the maximum at $312 \mathrm{~nm}$ disappeared and shifted to a new peak at $281 \mathrm{~nm}$ to give a typical lignin spectrum as previously found by Higuchi et al. ${ }^{5)}$ The absorption coefficients of all samples at $287 \mathrm{~nm}\left(a_{287} \cdot \mathrm{g}^{-1} \cdot \mathrm{cm}^{-1}\right)$ were considerably lower than that of $\mathrm{MBL}$ $\left(a_{287}=20.7\right)$ and followed in the order of $\mathrm{MBL}>\mathrm{W}-1>\mathrm{W}-2>\mathrm{LCC}-\mathrm{W}>\mathrm{W}-3$, as expected from the carbohydrate contents. 
Table I. Chemical Composition and Properties of the Lignin-Carbohydrate Complexes Containing Phenolic Acids

\begin{tabular}{|c|c|c|c|c|}
\hline \multirow{2}{*}{ Components } & \multicolumn{4}{|c|}{$\begin{array}{l}\text { Lignin-carbohydrate complexes } \\
\text { containing phenolic acids }{ }^{a}\end{array}$} \\
\hline & LCC-W & $\mathrm{W}-1$ & W-2 & $\mathrm{W}-3$ \\
\hline \multicolumn{5}{|l|}{ Carbohydrate content ${ }^{a}$} \\
\hline Neutral sugar & 48.0 & 31.4 & 34.7 & 67.9 \\
\hline Uronic acid & 2.0 & 1.5 & 1.6 & 3.6 \\
\hline \multicolumn{5}{|l|}{ Lignin content ${ }^{a}$} \\
\hline Klason & 22.7 & 44.0 & 40.1 & 6.3 \\
\hline Acid soluble & 3.1 & 3.4 & 3.3 & 3.4 \\
\hline Acetyl bromide & 42.3 & 56.2 & 52.1 & 22.3 \\
\hline \multicolumn{5}{|l|}{ Phenolic acid content ${ }^{a}$} \\
\hline trans-p-Coumaric acid & 4.79 & 8.01 & 5.84 & 0.69 \\
\hline trans-Ferulic acid & 0.30 & 0.14 & 0.21 & 0.42 \\
\hline Acetyl content ${ }^{a}$ & 6.4 & 4.6 & 6.0 & 6.6 \\
\hline$[\alpha]_{\mathrm{D}}^{25}(c, 0.5,50 \%$ dioxane $)$ & $-37.7^{\circ}$ & $-16.5^{\circ}$ & $-19.1^{\circ}$ & $-51.1^{\circ}$ \\
\hline$s_{20}^{\circ}(\mathrm{S})$ & n.d. ${ }^{b}$ & n.d. ${ }^{b}$ & 17.5 & 1.0 \\
\hline $\bar{M}_{w}$ & n.d. ${ }^{b}$ & n.d. ${ }^{b}$ & $7.0 \times 10^{5}$ & $4.3 \times 10^{3}$ \\
\hline $\bar{M}_{n}$ & n.d. ${ }^{b}$ & n.d. ${ }^{b}$ & $2.3 \times 10^{5}$ & $3.0 \times 10^{3}$ \\
\hline$\lambda_{\max }(50 \%$ dioxane, $\mathrm{nm})$ & 312,287 & 312,287 & 312,287 & 312,287 \\
\hline$\lambda_{\min }(50 \%$ dioxane, $\mathrm{nm})$ & 258 & 258 & 258 & 258 \\
\hline$a_{312}\left(1 \cdot \mathrm{g}^{-1} \cdot \mathrm{cm}^{-1}\right)$ & 6.7 & 10.3 & 10.2 & 1.8 \\
\hline$a_{287}\left(1 \cdot \mathrm{g}^{-1} \cdot \mathrm{cm}^{-1}\right)$ & 6.4 & 10.7 & 10.5 & 1.5 \\
\hline$a_{287} / a_{258}$ & 1.67 & 1.73 & 1.74 & 1.27 \\
\hline
\end{tabular}

a Values are expressed as a percentage of the dry weight of each lignin-carbohydrate complex containing phenolic acid.

$b$ Not determined.

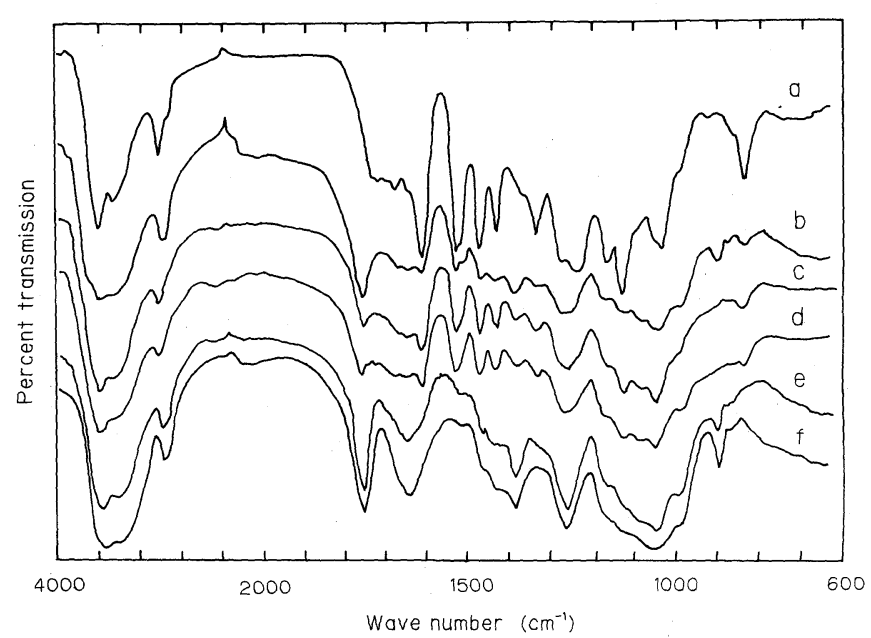

FIG. 4. IR Spectra of Bamboo Lignin-Carbohydrate Complexes Containing Phenolic Acids.

a, carbohydrate-less lignin; b, LCC-W; c, W-1; d, W-2; e, W-3; f, partially acetylated 4-O-methyl-glucuronoD-xylan. 
Table II. Neutral Sugar Composition of the Lignin-CaRbohydrate Complexes Containing PHENOLIC ACIDS

\begin{tabular}{lrrrr}
\hline \multirow{2}{*}{ Monosaccharides } & \multicolumn{3}{c}{$\begin{array}{c}\text { Lignin-carbohydrate complexes } \\
\text { containing phenolic acids }\end{array}$} \\
\cline { 2 - 5 } & LCC-W & W-1 & W-2 & W-3 \\
\cline { 2 - 5 } & 4.7 & 8.1 & 5.5 & 4.5 \\
L-Arabinose & 94.2 & 89.3 & 94.3 & 95.0 \\
D-Xylose & 0.7 & 2.2 & 0.1 & 0.3 \\
D-Galactose & 0.4 & 0.4 & 0.1 & 0.2 \\
D-Glucose & & & & \\
\hline
\end{tabular}

a Values are expressed as a percentage of the total neutral sugar.

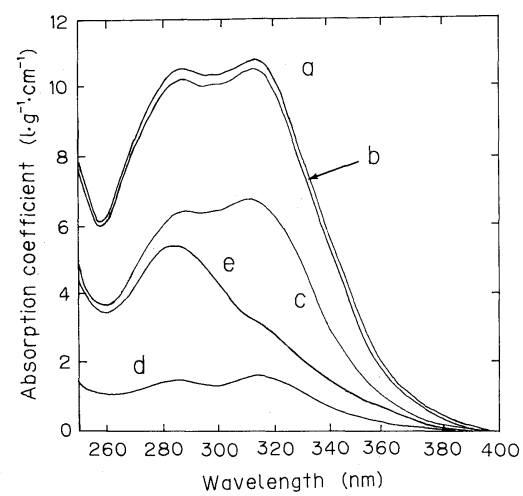

FIG. 5. UV Spectra of Bamboo Lignin-Carbohydrate Complexes Containing Phenolic Acids.

a, W-1; b, W-2; c, LCC-W; d, W-3; e, alkali-treated LCCW.

\section{Structural analyses of carbohydrate chains}

The absorption band at $895 \mathrm{~cm}^{-1}$ due to the $\beta$-glycosidic linkage of $\mathrm{D}$-xylopyranose residues $^{24)}$ became prominent as the carbohydrate content increased. The ${ }^{13} \mathrm{C}-\mathrm{NMR}$ spectra of the samples showed, in the anomeric carbon region, eight sharp signals between $85 \sim 110 \mathrm{ppm}$. A representative spectrum of $\mathrm{W}-$ 3 is shown in Fig. 6. The signals were assigned as shown in Table III, based on the data in the literature. ${ }^{14,27 \sim 29)}$ These results together with the results of methylation analyses (Table IV) indicate that the carbohydrate moiety of the samples has a $\beta$ - $(1 \rightarrow 4)$-linked D-xylopyranose backbone to which $\alpha$-L-arabinofuranose and 4$O$-methyl- $\alpha$-D-glucuronic acid residues are attached as side-chains on the $O-3$ and $O-2$ of the

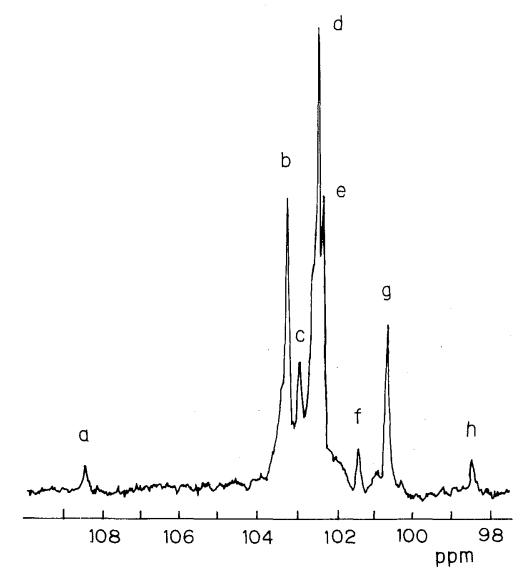

FIG. 6. ${ }^{13} \mathrm{C}-\mathrm{NMR}$ Spectrum of $\mathrm{W}-3$ at Anomeric Region.

Chemical shifts of the signals $(\mathrm{a} \sim \mathrm{h})$ were assigned as listed in Table III.

TABle III. ${ }^{13}$ C-NMR Data at ANOMERic Region of Lignin-CARBohydrate Complexes Containing PhenOlic ACIDS

\begin{tabular}{|c|c|c|}
\hline Signals $^{a}$ & $\begin{array}{c}\text { Chemical } \\
\text { shifts }^{b}\end{array}$ & Assignment of anomeric carbons ${ }^{c}$ \\
\hline a & 108.5 & Nonreducing end $\alpha$-L-Ara ${ }_{\mathrm{f}}$ \\
\hline $\mathrm{b}$ & 103.3 & 3-O-Acetylated $\beta$-D- $(1 \rightarrow 4)-\mathrm{D}-\mathrm{Xyl} \mathrm{p}_{\mathrm{p}}$ \\
\hline c & 103.0 & $\begin{array}{l}\beta \text {-( }(1 \rightarrow 4)-\mathrm{D}-\mathrm{Xyl} \mathrm{p}_{\mathrm{p}}, 2-O \text {-substituted } \\
\quad \text { with } \alpha-\mathrm{L}-\mathrm{Ara}_{\mathrm{f}}\end{array}$ \\
\hline $\mathrm{d}$ & 102.5 & Unsubstituted $\beta-(1 \rightarrow 4)-\mathrm{D}-\mathrm{Xyl}_{\mathrm{p}}$ \\
\hline $\mathrm{e}$ & 102.1 & $\begin{array}{l}\beta-(1 \rightarrow 4)-\mathrm{D}-\mathrm{Xyl}, 2-O \text {-substituted } \\
\quad \text { with } 4-O-\mathrm{Me}-\alpha-\mathrm{D}-\mathrm{Glc} A_{\mathrm{p}}\end{array}$ \\
\hline $\mathrm{f}$ & 101.5 & $2,3-\mathrm{Di}-O$-acetylated $\beta$ - $(1 \rightarrow 4)-\mathrm{D}-\mathrm{Xyl} \mathrm{p}_{\mathrm{p}}$ \\
\hline $\mathrm{g}$ & 100.7 & 2-O-Acetylated $\beta$ - $(1 \rightarrow 4)-\mathrm{D}-\mathrm{Xyl}_{\mathrm{p}}$ \\
\hline $\mathrm{h}$ & 98.5 & Nonreducing end $4-O-\mathrm{Me}-\alpha-\mathrm{D}-\mathrm{Glc} A_{\mathrm{p}}$ \\
\hline
\end{tabular}

a Specified in Fig. 6.

$b$ In ppm relative to internal 1,4 -dioxane $(64.70 \mathrm{ppm}$ from TMS).

c $\beta$ - $(1 \rightarrow 4)-\mathrm{D}-\mathrm{Xyl}_{\mathbf{p}}=\beta$ - $(1 \rightarrow 4)$-linked $\mathrm{D}$-xylopyranosyl residues, etc.

D-xylopyranose residues, respectively.

To obtain more information on the structure of the carbohydrate moiety and ligninand phenolic acid-carbohydrate linkages, we used periodate oxidation analysis. In all native samples, L-arabinose and hexoses were completely degraded, while half of the Dxylose residues remained unattacked (Table V). After de-esterification, however, only a small amount of D-xylose residues remained. 
It seems that the D-xylose residues remaining after periodate oxidation of the de-esterified samples are linked between lignin and 4-Omethyl-D-glucuronic acid residues, but the Dxylose residues remaining in the native samples may include additional D-xylose residues partially acetylated at the $O-2$ and/or $O-3$ positions. The formation of a large amount of glycerol supports the presence of $(1 \rightarrow 4)$-linked linear carbohydrate chains in the samples.

From these results, it may be concluded that the carbohydrate moieties of the Mosobamboo lignin-carbohydrate complexes containing phenolic acids were composed of a linear backbone of $\beta$-(1 $1 \rightarrow 4)$-linked-Dxylopyranosyl residues with approximately every thirty residues carrying one or two Larabinofuranose and one 4-O-methyl-D-

Table IV. Methyl Ethers from the Hydrolysate of THE Lignin-CARBOHYDRATE COMPLEXES Containing Phenolic Acids

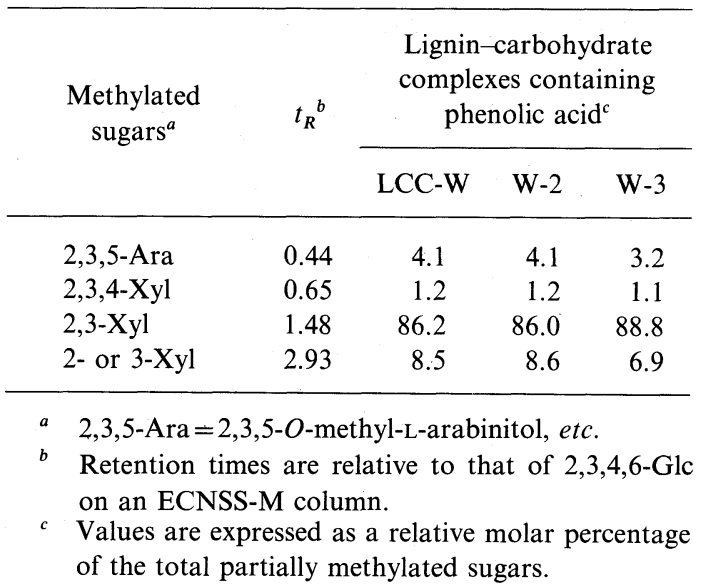

glucuronic acid residues as pendants. The results also showed that the carbohydrate moieties of Moso-bamboo lignin-carbohydrate complexes containing phenolic acids are similar to xylans isolated from Madake ${ }^{30}$ and other gramineous plants. ${ }^{31)}$

\section{Effects of alkali on lignin-carbohydrate com- plexes containing phenolic acids}

The amount of phenolic acids saponified with alkali was quantitatively estimated by GLC (Table I); all the samples contained esterified trans-p-coumaric and trans-ferulic acids. The increase of trans-p-coumaric acid was positively correlated with lignin content, but the reverse relationship was observed for trans-ferulic acid, i.e., trans-ferulic acid content was correlated with carbohydrate content, similar to the results of Shimada. ${ }^{32)}$ Quite similar results were also obtained with bagasse lignin-carbohydrate complexes. ${ }^{81}$ These results suggest that the saponified trans-p-coumaric and trans-ferulic acids were esterified to lignin and carbohydrate, respectively. $p$-Coumaric acid has been demonstrated to be esterified at $\mathrm{C}_{\alpha}$ and $\mathrm{C}_{\gamma}$ of the side chain of the phenylpropane unit in bamboo lignin. ${ }^{33,34)} \mathrm{We}$ have isolated $3^{2}-\alpha$-L-arabinofuranosylxylobiose feruloylated at $\mathrm{C}_{5}-\mathrm{OH}$ of an $\mathrm{L}$-arabinofuranose residue from bagasse LCC. $^{35)}$

To analyze the linkages between lignin and carbohydrates, the water-soluble fraction obtained after alkali treatment was subjected to gel filtration on Sepharose 4B (Fig. 2b). The elution profile showed that the $\mathrm{W}-1$ and $\mathrm{W}-2$

TABle V. COMPosition OF THE Hydrolysate OF THE Lignin-CARBOHYdRATE Complexes Containing Phenolic Acids after Periodate Oxidation

\begin{tabular}{|c|c|c|c|c|c|c|}
\hline \multirow{3}{*}{ Components } & \multicolumn{6}{|c|}{$\begin{array}{l}\text { Lignin-carbohydrate complexes } \\
\text { containing phenolic acids }{ }^{a}\end{array}$} \\
\hline & \multicolumn{2}{|c|}{ LCC-W } & \multicolumn{2}{|c|}{ W-2 } & \multicolumn{2}{|c|}{ W-3 } \\
\hline & A & B & A & B & A & B \\
\hline Glycerol & 50.3 & 90.0 & 51.1 & 89.0 & 48.4 & 89.5 \\
\hline D-Xylose & 49.6 & 10.0 & 48.9 & 11.0 & 51.6 & 10.5 \\
\hline
\end{tabular}

a Values are expressed as a relative molar percentage of the component sugars: A, original sample; B, deacetylated sample. 
fractions completely disappeared and a new peak containing lignin and phenolic acids appeared after the elution of W-3. The hydrophobic interaction chromatography of the same alkali-treated sample on Octyl-Sepharose CL-4B showed that only $45.5 \%$ of the lignin and $42.2 \%$ of the carbohydrate put on the gel were adsorbed on the gel, and that the elution profile of lignin in the unadsorbed fraction did not coincide with that of carbohydrate (Fig. 3c). These results suggest the presence of the two different types of linkages between lignin and carbohydrate, one is alkali-labile and the other is stable.

Acknowledgment. The authors thank Mr. T. Katsuyama for his technical assistance in the preparation of the lignin-carbohydrate complexes containing phenolic acids.

\section{REFERENCES}

1) Y. Z. Lai and K. V. Sarkanen, "Lignins," ed. by K. V. Sarkanen and C. H. Ludwig, Wiley-Interscience, New York, 1971, p. 294.

2) O. P. Grushnikov and N. N. Shorygina, Russ. Chem. Rev., 39, 684 (1970).

3) T. Higuchi and I. Kawamura, Holzforsch., 20, 16 (1966).

4) T. Yamazaki and T. Higuchi, Mokuzai Gakkaishi, 17, 117 (1971).

5) T. Higuchi. Y. Ito, M. Shimada and I. Kawamura, Phytochemistry, 6, 1551 (1967).

6) J. Azuma, N. Takahashi and T. Koshijima, Carbohydr. Res., 93, 91 (1981).

7) J. Azuma, N. Takahashi, M. Isaka and T. Koshijima, Mokuzai Gakkaishi, 31, 587 (1985).

8) A. Kato, J. Azuma and T. Koshijima, Holzforsch., 38, 141 (1984).

9) M. Dubois, K. A. Gilles, J. K. Hamilton, P. A. Revers and F. Smith, Anal. Chem., 28, 350 (1959).

10) J. T. Galambos, Anal. Biochem., 19, 119 (1967).

11) D. B. Johnson, W. E. Moore and L. C. Zank, Tappi, 44, 793 (1961).
12) W. F. Dudman and C. T. Bishop, Can. J. Chem., 46 , 3079 (1968).

13) M. Tomoda, S. Kaneko and S. Nakatsuka, Chem. Pharm. Bull., 23, 430 (1975).

14) Š. Karácsonyi, J. Alföldi, M. Kubačková and Ľ. Stupka, Cellulose Chem. Technol., 17, 637 (1983).

15) T. E. Timell and A. J. Mian, Tappi, 44, 788 (1961).

16) R. D. Hartley, J. Chromatogr., 54, 335 (1971).

17) R. D. Hartley and E. C. Jones, J. Chromatogr., 107, 213 (1975).

18) S. Hakomori, J. Biochem., 55, 205 (1964).

19) K. Wallenfels, G. Bechtler, R. Kuhn, H. Trischmann and H. Egge, Angew. Chem., 75, 1014 (1963).

20) B. Lindberg, "Methods in Enzymology," Vol. XXVIII, ed. V. Ginsberg, Academic Press Inc., New York, 1972, p. 178.

21) P. Albersheim, D. J. Nevins, P. D. English and A. Karr, Carbohydr. Res., 5, 340 (1967).

22) N. Takahashi, J. Azuma and T. Koshijima, Carbohydr. Res., 107, 161 (1982).

23) J. Rabier, M. Vijayalakshmi, C. Lambert and J. Porath, Phytochemistry, 23, 7 (1984).

24) T. Fukuda and T. Kanda, Mokuzai Gakkaishi, 22, 564 (1976).

25) F. W. Whitmore, Phytochemistry, 17, 421 (1978).

26) S. A. Barker, E. J. Bourne and D. H. Whiffen, "Methods of Biochemical Analysis," Vol. III, ed. by D. Glick, Interscience, New York, 1956, p. 213.

27) J. Azuma and T. Koshijima, Mokuzai Kenkyu. Shiryo, 17, 132 (1983).

28) J. Azuma and T. Koshijima, Wood Res., 69, 12 (1983).

29) F. Reicher, J. B. C. Corrêa and P. A. J. Gorin, Carbohydr. Res., 135, 129 (1984).

30) E. Maekawa and K. Kitao, Agric. Biol. Chem., 37, 2073 (1973).

31) K. C. B. Wilkie, "Advances in Carbohydrate Chemistry and Biochemistry," Vol. 36, ed. by R. S. Tipson and D. Horton, Academic Press, New York, 1979, p. 215.

32) M. Shimada, Wood Res., 53, 19 (1972).

33) M. Shimada, T. Fukuzuka and T. Higuchi, Tappi, 54, 72 (1971).

34) Y. Nakamura and T. Higuchi, Holzforsch., 30, 187 (1976).

35) A. Kato, J. Azuma and T. Koshijima, Chem. Lett., 137 (1983). 